\title{
Two Cases of Giant Melanocytoma (Hyperpigmented Magnocellular Nevus)
}

\author{
David I.T. Sia ${ }^{a} \quad$ Jorge Agib Parampal Grewal ${ }^{\mathrm{a}} \quad$ Laurie Russell $^{\mathrm{c}} \quad$ Ezekiel Weis ${ }^{\mathrm{a}} \mathrm{b}$ \\ ${ }^{a}$ Department of Ophthalmology and Visual Sciences, Faculty of Medicine and Dentistry, University of Alberta, \\ Edmonton, AB, Canada; ${ }^{b}$ Department of Surgery, Faculty of Medicine and Dentistry, University of Calgary, \\ Calgary, AB, Canada; ' ${ }^{\circ}$ epartment of Laboratory Medicine and Pathology, Faculty of Medicine and Dentistry, \\ University of Alberta, Edmonton, $A B$, Canada
}

\section{Established Facts}

- $10-15 \%$ of optic disc melanocytomas show subtle enlargement over years.

- $1-2 \%$ of these are associated with malignant transformation.

- The incidence for uveal melanocytomas is unknown.

\section{Novel Insights}

- Uveal melanocytomas can grow to very large proportions without histological evidence of malignant transformation.

- Uveal melanocytomas can be associated with extrascleral extension after biopsy and rapid growth without histological evidence of malignant transformation.

\section{Keywords}

Melanocytoma · Magnocellular nevus · Giant

melanocytoma $\cdot$ Choroidal tumor · Melanoma

\begin{abstract}
Melanocytoma or hyperpigmented magnocellular nevus is a variant of melanocytic nevus that is most commonly seen in the optic nerve, but has also been reported to occur in the iris, ciliary body, choroid, sclera, and conjunctiva. We present two cases of giant uveal melanocytoma with histopathology. The first case occurred in a 10-year-old girl who presented with decreased vision in the right eye and a mushroomshaped pigmented choroidal lesion measuring $15.5 \mathrm{~mm}$ in
\end{abstract}

apical height. The lesion was abutting the lens but not causing a cataract. This was diagnosed as a choroidal melanocytoma on open scleral window biopsy. The second case was in a 68-year-old lady, referred for a left nasal pigmented choroidal lesion measuring $8 \mathrm{~mm}$ in apical height and having a mushroom configuration. The lesion grew to $8.6 \mathrm{~mm}$ in height and was complicated by a vitreous hemorrhage and rhegmatogenous retinal detachment and was treated with iodine-125 plaque brachytherapy. Subsequently, the treated eye became a painful phthisical eye and was enucleated. Histopathology confirmed melanocytoma with extrascleral extension but without malignant transformation. Features of melanocytoma and other very large cases reported in the literature are discussed. (c) 2020 S. Karger AG, Basel karger@karger.com

(C) 2020 S. Karger AG, Basel

www.karger.com/oop

Karger ${ }^{\prime}=$
Ezekiel Weis

Department of Ophthalmology, University of Alberta 2319 Royal Alexandra Hospital, Active Treatment Centre

Edmonton, AB T5H 3V9 (Canada)

ezekielweis@gmail.com 


\section{Introduction}

Melanocytoma or hyperpigmented magnocellular nevus is a variant of melanocytic nevus considered to be a congenital lesion [1]. The term melanocytoma was introduced in 1962 by Zimmerman and Garron [2] to describe a benign tumor of the optic nerve head composed of uniform, densely pigmented, large polyhedral cells. Melanocytomas may also less commonly involve the iris [3], ciliary body [4], choroid [5], sclera [6], and conjunctiva [7]. The incidence of uveal melanocytoma is uncertain, since only those confirmed histopathologically are reported in the literature. In a study of pigmented intraocular tumors by Howard and Forrest [8], only $0.6 \%$ were found to be melanocytomas. In another review of 189 iris or ciliary body lesions originally diagnosed as melanomas, $5 \%$ were found to be melanocytomas [9]. Melanocytomas are generally considered to be stable lesions; however, some cases may exhibit growth as well as malignant transformation [10]. The exact incidence of this is unknown in uveal melanocytomas, but for melanocytoma of the optic disk, $10-15 \%$ show subtle enlargement over years, and $1-2 \%$ are associated with malignant transformation [10]. We present two cases of giant uveal melanocytomas and their associated complications.

\section{Case Report}

\section{Case 1}

A 10-year-old Native American girl presented with a 1-year history of decreased vision in her right eye. Her grandmother noted that her right eye had become exotropic 2 years prior and she occasionally bumped into things on her right side. Past ocular history and past medical history were unremarkable. In her family history, her father required an enucleation for an unknown cause. She was not on regular medications. On examination, she had best corrected visual acuities of hand motions vision OD and 20/40 OS. Intraocular pressures were normal at $15 \mathrm{~mm} \mathrm{Hg} \mathrm{OD} \mathrm{and} 18 \mathrm{~mm}$ Hg OS. The anterior segment was normal in both eyes with no sentinel vessels. The lens was clear OU. There was a large pigmented lesion arising from the inferior aspect of the posterior pole of the right eye. The lesion abutted the lens and was heavily pigmented with a velvety surface (Fig. 1a). The rest of the fundus in the right eye showed speckled retinal pigment epithelium changes and mildly sclerotic vessels. The left fundus was normal.

On ultrasonography (US), B-scan revealed a large solid mushroom-shaped lesion (Fig. 1b) with a maximum height of $15.5 \mathrm{~mm}$ and largest basal diameter of $19.4 \mathrm{~mm}$, which had no intrinsic vascularity and showed high internal reflectivity on A-scan (Fig. 1c). On magnetic resonance imaging, the lesion was hyperintense on T1 sequences, hypointense on T2 sequences, and showed no contrast enhancement (Fig. 2). The globe, orbit, and optic nerve sheath complex were normal on both sides.

Two Cases of Giant Melanocytoma
The differential diagnosis at this stage included choroidal hemorrhage, adenoma or adenocarcinoma of the retinal pigment epithelium, melanocytoma, and choroidal melanoma.

She underwent a fine-needle aspiration biopsy (FNAB) of the lesion, which retrieved a heavily pigmented hypocellular sample, with a group of cells obscured by associated pigment that precluded further interpretation. A subsequent open scleral window biopsy was performed, which revealed densely pigmented cells with bland nuclei post bleaching. There was no evidence of malignancy. Immunostains for neural crest markers and iron stain were negative. A diagnosis of melanocytoma was made.

Case 2

A 68-year-old Native American female presented with nonlocalizing symptoms of blurred peripheral vision of an unknown duration. Past ocular history was unremarkable. Past medical history was significant for dyslipidemia, hypertension, and osteoarthritis. She was taking rabeprazole and perindopril.

On initial assessment, best corrected visual acuities were 20/40 OD and 20/30 OS. The intraocular pressures were normal. Anterior exam demonstrated mild, symmetric nuclear sclerotic cataracts. Posterior segment exam of the right eye was within normal limits. Posterior segment exam of the left eye revealed an elevated pigmented mass in the nasal periphery (Fig. 3a, b). Additionally, there was an epiretinal membrane with pigment dusting in the posterior pole and inferior pigment clumping in the vitreous (Fig. 3a).

Initial B-scan US demonstrated a uniform, solid, mushroomshaped lesion involving the nasal choroid and ciliary body with a maximal height of $8.0 \mathrm{~mm}$ (Fig. 3c). On A-scan US, there was a high internal reflectivity with a decrescendo signal (Fig. 3c). On computed tomography, the lesion was well defined and hyperdense without calcification.

A metastatic workup was obtained including computed tomography of the chest, abdomen, and pelvis. This did not demonstrate a primary neoplasm. Further, a positron emission tomography scan did not demonstrate any metastatic disease. Interestingly, the intraocular lesion was not fludeoxyglucose avid.

Given the atypical clinical features, a trans-scleral FNAB was performed. This was initially nondiagnostic with an acellular sample with brownish amorphous material. A repeat aspirate was obtained, which demonstrated heavy coarse pigmentation and large polygonal-shaped cells with small nuclei. There were no spindleshaped cells. This was felt to represent a melanoma, melanocytoma, or a low-grade neoplasm of the retinal pigment epithelium. Due to limited sampling, a definitive diagnosis could not be reached; however, a low-grade melanocytic lesion was suggested. The patient was offered repeat biopsy but elected for observation.

On follow-up examination, significant growth of the lesion to 8.6 $\mathrm{mm}$ in height occurred, and plaque treatment was advised. However, the patient initially elected to observe due to the risk of vision loss with radiation treatment. During this period, she unfortunately developed a vitreous hemorrhage and rhegmatogenous retinal detachment (retinal break on surface of tumor). This was treated with pars plana vitrectomy with silicone oil tamponade. The lesion appeared to grow further on clinical examination, and despite the limited US examination, there appeared to be further growth by US. Due to the possibility for malignant transformation, the patient elected to proceed with iodine-125 plaque brachytherapy. At that stage, the dimensions were $9.2 \mathrm{~mm} \times 8.8 \mathrm{~mm}$ in base and $8.7 \mathrm{~mm}$ in height. Since the diagnosis was not clear, a repeat FNAB for cytology and gene 


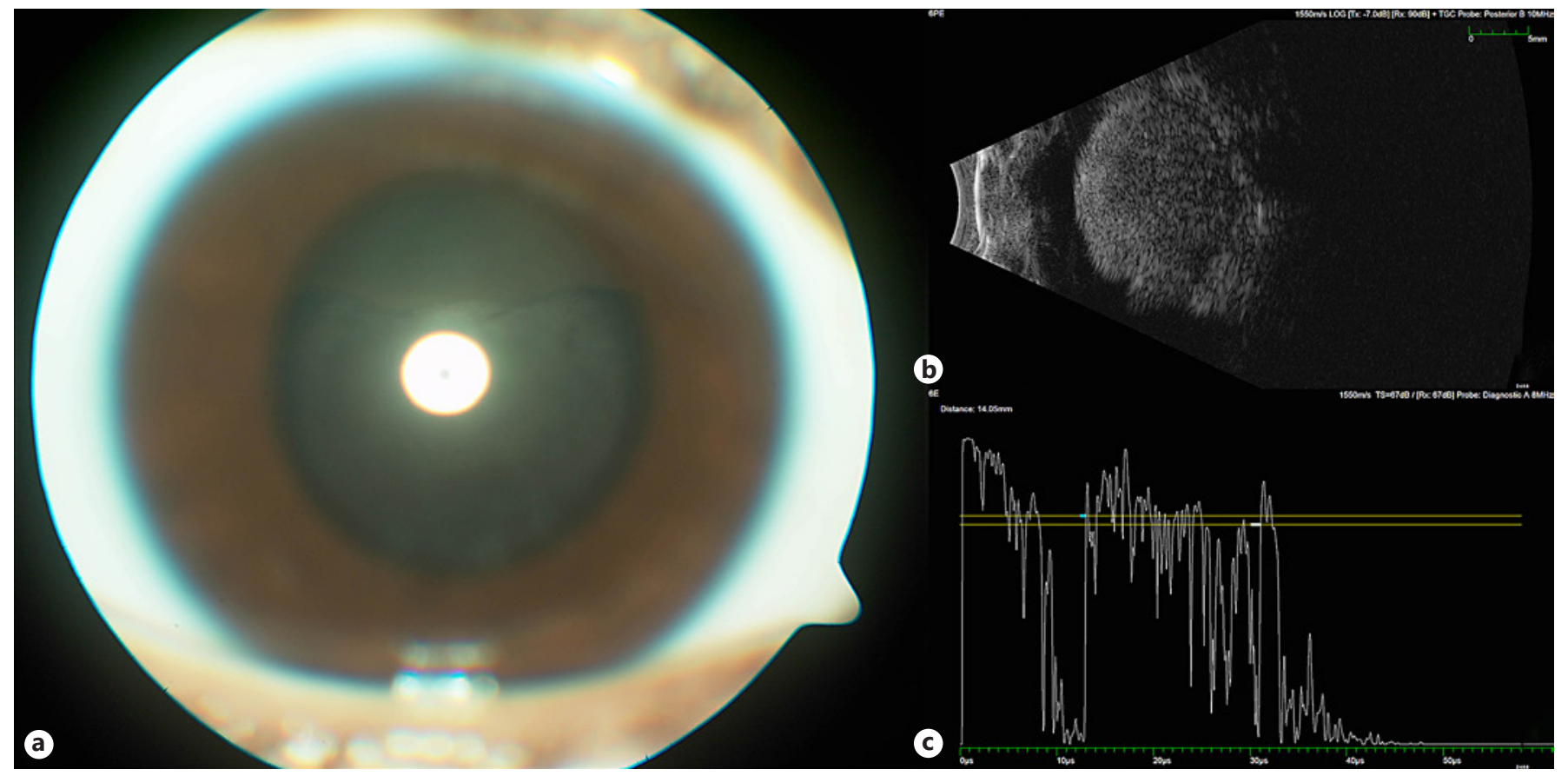

Fig. 1. Color photograph of the right eye (a) showing a heavily pigmented choroidal lesion abutting the lens from the inferior fundus. B-scan ultrasonography (b) of the right eye, transverse $6 \mathrm{E}$ position showing the mushroomshaped solid lesion. A-scan ultrasonography (c) showing high internal reflectivity of the lesion.
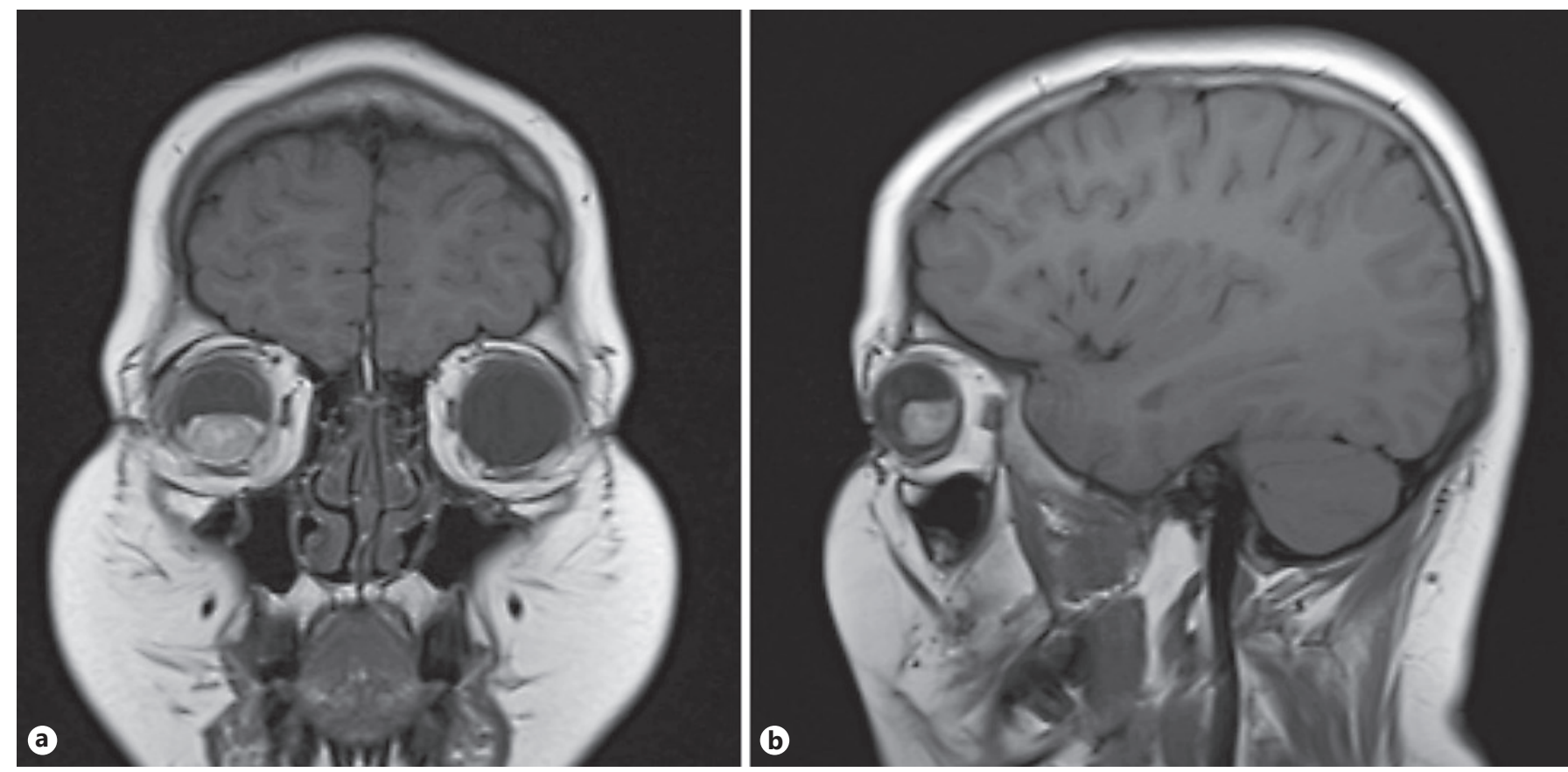

Fig. 2. Magnetic resonance imaging T1-weighted sequence. Coronal slice (a) showing the hyperintense lesion arising from the inferior fundus. Sagittal slice (b) showing the lesion occupying almost half of the globe. 


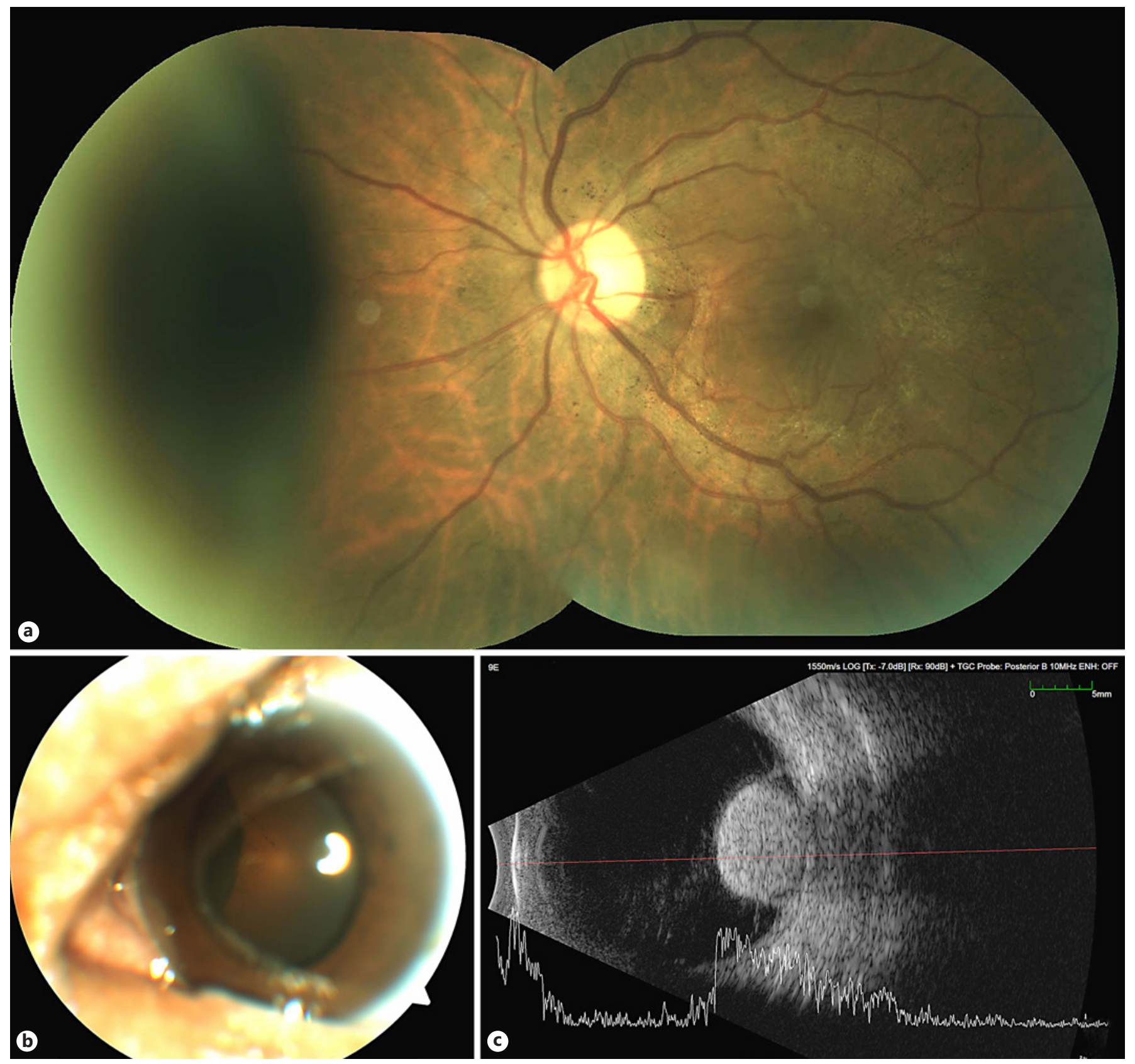

Fig. 3. Color photograph of left fundus (a) showing the large pigmented lesion arising from the nasal periphery. There is pigment dusting on the retina in the posterior pole and an epiretinal membrane. Color photograph of the left anterior segment (b) shows the pigmented lesion located nasally behind the lens. B-scan ultraso-

expression profiling was performed in case this lesion turned out to be a melanoma. Cytology at the time of plaque placement demonstrated numerous heavily pigmented melanophages and rare cytologic atypia in some pigmented cells. Melanoma was suspected, and gene expression profile demonstrated a class $1 \mathrm{~A}$ signature. Six months following treatment, the patient developed a painful, phthis- nography with A-scan overlay (c) showing a mushroom-shaped solid lesion with high internal reflectivity and decrescendo pattern. There is also surrounding serous retinal detachment and orbital shadowing.

ical eye with light perception vision. Her symptoms were not controlled with conservative measures and she elected for enucleation.

\section{Pathology}

Histopathological assessment of the enucleation demonstrated a large melanocytoma of the ciliary body and choroid 10 

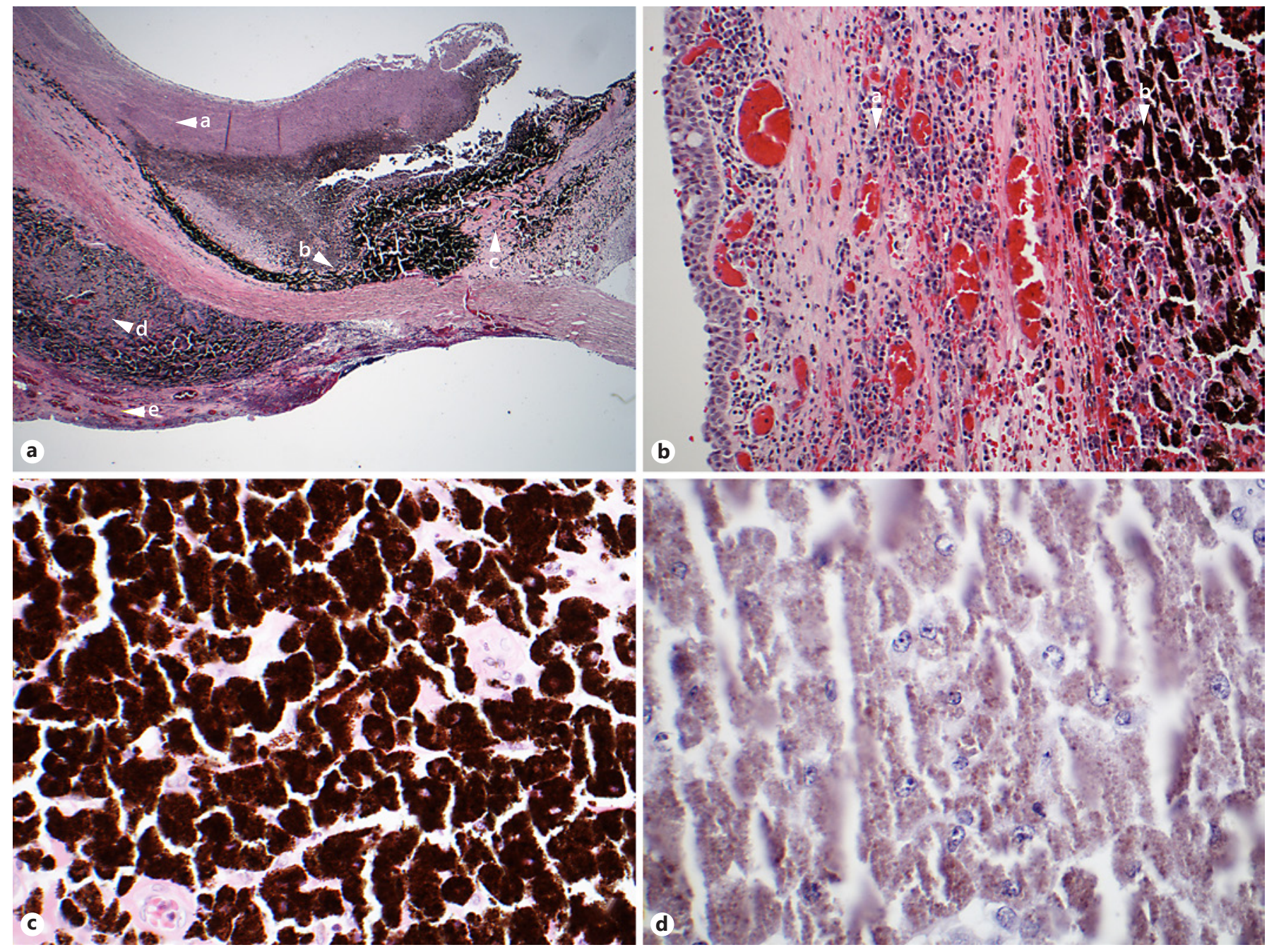

Fig. 4. a Micrograph (original magnification $\times 20$ ) demonstrating the melanocytoma involving the choroid and ciliary body; necrotic tumor (arrow a), viable tumor (arrow b), ciliary body (arrow c), extrascleral extension (arrow d), and inflamed hemorrhagic conjunctiva (arrow e). b Micrograph (original magnification $\times 200$ ) demonstrating the inflamed and hemorrhagic conjunctiva (arrow a) and the extrascleral extension of tumor with inflammatory in-

$\mathrm{mm}$ in diameter. Extrascleral extension was noted (Fig. 4a). Extensive necrosis with inflammation and fibrosis was noted with no component suggestive of malignant transformation (Fig. 4a, b). There was extensive serous retinal detachment with copious pigment dispersion admixed with pigment-containing histiocytes. Tumor cells demonstrated heavy cytoplasmic pigmentation (Fig. 4c). Bleached sections demonstrated large polygonal cells with fairly uniform, round to vesicular nuclei with small nucleoli (Fig. 4d). Mitotic figures were not identified. Immunohistochemistry was positive for vimentin and negative for pankeratin, LMK, EMA, MART-1, S100, and HMB-45 in tumor cells. filtrate (arrow b). c Micrograph (original magnification $\times 400$ ) demonstrating the tumor cells with heavy cytoplasmic pigmentation. d Micrograph (original magnification $\times 600$ ) demonstrating a bleached section of viable tumor tissue, showing large polygonal cells with mitotically inactive nuclei with small nucleoli and bleached cytoplasmic pigment in coarse granules.

\section{Discussion}

In rare cases, the clinical appearance of melanocytoma of the choroid and ciliary body may be difficult to differentiate from a malignant melanoma. Compared to melanoma, melanocytomas of the choroid and ciliary body are more likely to have a rough or corrugated surface, to be dark brown or black, to undergo necrosis with a central crater, and to have pigment dispersion [1]. Choroidal melanocytomas are commonly placoid or dome-shaped in 
configuration, but can assume a mushroom shape if the tumor breaks through Bruch's membrane $[1,11]$. Melanocytomas can also grow diffusely and involve all layers of the uvea (iris, ciliary body, and choroid) [12]. Our first case was the larger of the two, but did not have pigment dispersion, while our second case had pigment clumping in the vitreous and on the posterior pole. Both of our cases displayed a mushroom-shaped appearance more common in malignant melanomas. Although the large tumor in our first case was abutting the lens, it did not cause a cataract.

On US, melanocytomas typically have a high internal reflectivity on A-scan and acoustic solidity with B-scan as was seen in our two cases [1]. However, cases of melanocytoma showing low internal reflectivity and acoustic hollowness have been reported [11].

Shanmugam et al. [13] reported a similar case of a giant ciliary body melanocytoma in a 15 -year-old male measuring $14.2 \mathrm{~mm}$ in apical height on US. The mass had a solid dark brown appearance and was abutting the inferior part of the lens, causing a focal cataract. There was shallow anterior chamber, peripheral anterior synechiae, and heterochromia of the inferior iris from pigment clump deposition. US showed a homogenous mass with moderate to high internal reflectivity. Magnetic resonance imaging revealed the mass to be hypo-/isointense on T1 and hypointense on T2 with minimal contrast enhancement. An incisional biopsy confirmed the diagnosis of melanocytoma with no increased mitotic activity. Following incisional biopsy, the lesion underwent rapid extra ocular growth and the lesion was treated with ruthenium-106 brachytherapy with successful regression in size (see Table 1). Our second case displayed progressive enlargement following her second FNAB, and on the enucleation specimen, there was evidence of extrascleral extension.

Brownstein et al. [14] reported a case of a peripapillary melanocytoma in a 5-year-old girl, with maximal dimensions of $8 \mathrm{~mm}$ in base and $6 \mathrm{~mm}$ in height on B-scan US. There was high internal reflectivity on A-scan. The tumor had a heavily pigmented base and orange-brown pigmentation near the summit. A clinical diagnosis of malignant melanoma was made and the eye enucleated. Histopathology confirmed the diagnosis of melanocytoma with a large central area of necrosis. There was no evidence of malignant transformation within the specimen [14].

Lehman et al. [15] reported a case of a giant choroidal melanocytoma in a 2-year-old boy who presented with exotropia, leukocoria, and a total retinal detachment. Bscan US revealed a large mushroom-shaped intraocular lesion with foci of high internal reflectivity, which was interpreted as calcification. The tumor measured $9 \mathrm{~mm}$ at the base and $12 \mathrm{~mm}$ in height. The lesion was clinically diagnosed to be a retinoblastoma and the eye enucleated. Histopathology revealed a heavily pigmented tumor with large areas of necrosis. Bleached sections revealed the cells to be consistent with melanocytoma. The authors felt that areas of necrosis within the tumor were highly reflective on US and had led to misinterpretation as focal calcifications [15].

El-Harazi et al. [16] reported a case of giant ciliary body melanocytoma in a 55-year-old man who presented with decreased vision and intermittent flashes. The tumor measured $8.5 \mathrm{~mm}$ in apical height and $15.5 \mathrm{~mm}$ in maximal base. Several months later, the tumor increased in size and caused a total retinal detachment with raised intraocular pressure and pain. The eye was subsequently enucleated. Histopathology confirmed melanocytoma with no evidence of malignant transformation.

Melanocytomas are known to cause complications including raised intraocular pressure (melanocytomalytic glaucoma) [17], necrosis and pigment dispersion [18], retinal and vitreous seeding [19], extrascleral extension [20], exudative retinal detachment [16], vitreous hemorrhage [21], and malignant transformation [12]. No definite risk factors for malignant transformation have been identified for uveal melanocytoma and the precise incidence is unknown, since melanocytoma may be impossible to differentiate from other uveal nevi. In the case of an optic disk melanocytoma, subtle enlargement does not necessarily imply malignant change, but more profound and rapid growth is generally considered a sign of malignant transformation into melanoma [10]. Other features suggestive of malignant transformation in melanocytoma of the optic disk are progressive vitreous seeding, extensive involvement of the optic nerve with severe visual loss, and an initial lesion originating exclusively from optic nerve $[10,22]$. Despite this, distinguishing malignant transformation is still difficult as severe necrosis of a benign melanocytoma can produce similar signs and symptoms [10]. About $10-15 \%$ of melanocytoma of the optic disk show subtle enlargement over several years [23]. The main predictive risk factor for growth is an initial thickness of $1.5 \mathrm{~mm}$ or greater at the time of first diagnosis [23].

In both of our cases, the initial FNABs were nondiagnostic. In these situations, performing a second biopsy via a scleral window if possible, as was performed in our first case, is a reasonable choice. Despite obtaining repeated samples, often interpretation of these specimens is chal- 


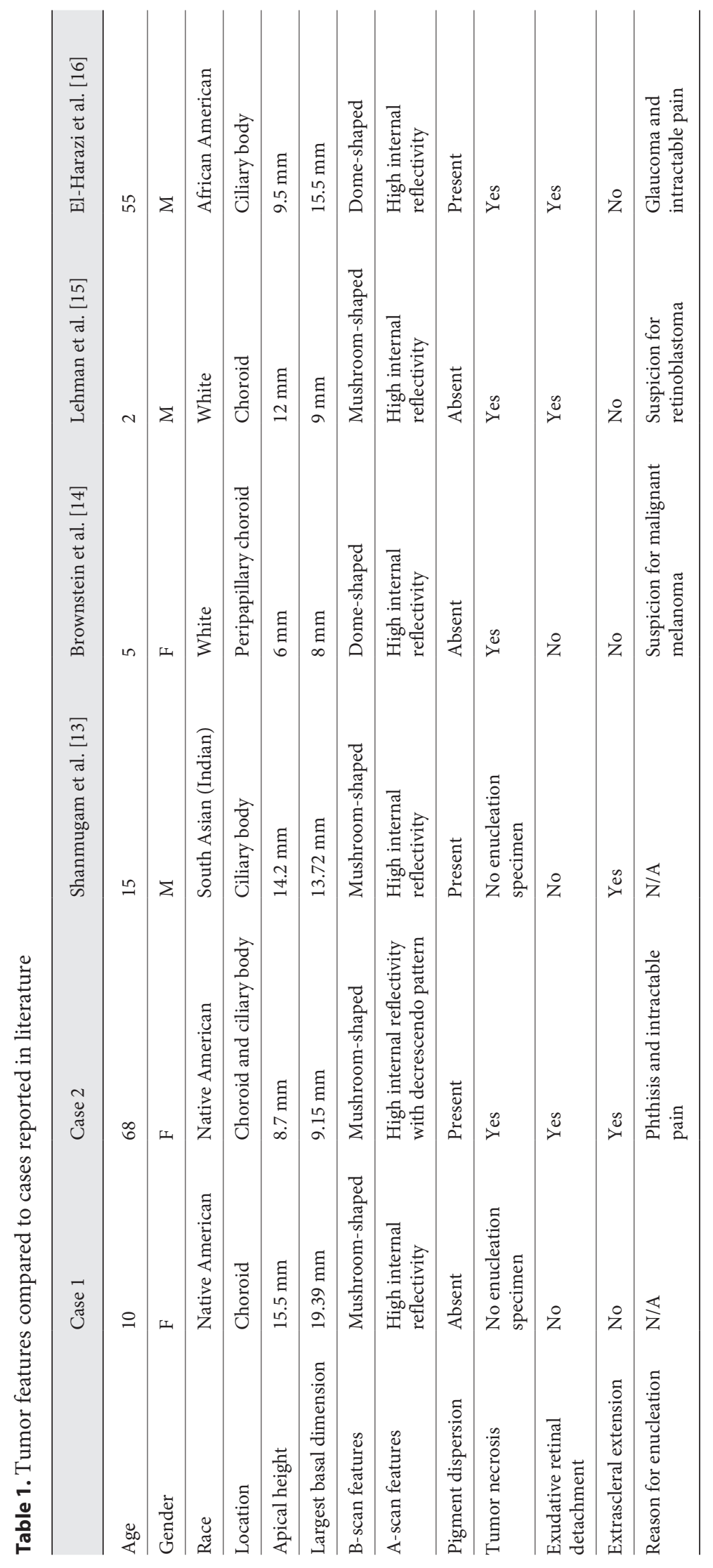


lenging. The decision to treat should then be individualized to the patient and based on clinical judgement.

Both of our cases of large melanocytomas were in $\mathrm{Na}$ tive American females. Together with previously reported cases, large melanocytomas seem to have a disproportionate representation in darker pigmented races, representing 4 out of 6 cases (Table 1). This appears to be a greater proportion than has been previously reported when a series of all melanocytomas were described $[1,10]$. This finding suggests that large melanocytomas may be more common in darker pigmented races, but due to the small numbers in the literature, this association cannot be verified.

Our report highlights two cases of giant uveal melanocytoma and the associated features of progressive enlargement possibly related to necrosis, mushroom-shaped configuration, pigment dispersion, vitreous hemorrhage, rhegmatogenous retinal detachment, and extrascleral extension without malignant transformation.

\section{Acknowledgement}

We acknowledge Dr. Cherif Garady for obtaining the histopathology slides.

\section{Statement of Ethics}

This report complies with the World Medical Association Declaration of Helsinki. Ethics approval was obtained from the Health Research Ethics Board of Alberta (Ethics ID: HREBA.CC-170625_REN1). Written informed consent was obtained from the patients for the publication of their case (including publication of images).

\section{Disclosure Statement}

The authors have no conflicts of interest to declare.

\section{Funding Sources}

None.

\section{Author Contributions}

David I.T. Sia: substantial contribution to acquisition, analysis, interpretation of data for the work; drafting the work, revising it for critically important intellectual content; final approval of version to be published; agreed to be accountable for all aspects of the work in ensuring that questions related to the accuracy or integrity of any part of the work are appropriately investigated and resolved. Jorge Agi: drafting the work, revising it for critically important intellectual content; final approval of version to be published; agreed to be accountable for all aspects of the work in ensuring that questions related to the accuracy or integrity of any part of the work are appropriately investigated and resolved. Parampal Grewal: drafting the work, revising it for critically important intellectual content; final approval of version to be published; agreed to be accountable for all aspects of the work in ensuring that questions related to the accuracy or integrity of any part of the work are appropriately investigated and resolved. Laurie Russell: drafting the work, revising it for critically important intellectual content; final approval of version to be published; agreed to be accountable for all aspects of the work in ensuring that questions related to the accuracy or integrity of any part of the work are appropriately investigated and resolved. Ezekiel Weis: substantial contribution to conception or design of the work; drafting the work, revising it for critically important intellectual content; final approval of version to be published; agreed to be accountable for all aspects of the work in ensuring that questions related to the accuracy or integrity of any part of the work are appropriately investigated and resolved.

\section{References}

1 Shields JA, Shields CL, Eagle RC Jr. Melanocytoma (hyperpigmented magnocellular nevus) of the uveal tract: the 34th G. Victor Simpson lecture. Retina. 2007 Jul-Aug;27(6): 730-9.

2 Zimmerman LE, Garron LK. Melanocytoma of the optic disk. Int Ophthalmol Clin. 1962; 2:431-40.

3 Demirci H, Mashayekhi A, Shields CL, Eagle RC Jr, Shields JA. Iris melanocytoma: clinical features and natural course in 47 cases. Am J Ophthalmol. 2005 Mar;139(3): 468-75.

4 LoRusso FJ, Boniuk M, Font RL. Melanocytoma (magnocellular nevus) of the ciliary body: report of 10 cases and review of the literature. Ophthalmology. 2000 Apr;107(4): 795-800.
5 Ahmad SS, Lad L, Ghani SA. A case of choroidal melanocytoma mimicking a choroidal melanoma. Saudi J Ophthalmol. 2015 Jul-Sep; 29(3):242-5.

6 Lee JS, Smith RE, Minckler DS. Scleral melanocytoma. Ophthalmology. 1982 Feb;89(2): 178-82.

7 Herwig-Carl MC, Loeffler KU, Grossniklaus HE. Melanocytoma of the Conjunctiva: Clinicopathologic Features of Three Cases. Ocul Oncol Pathol. 2019 Jun;5(4):290-7.

8 Howard GM, Forrest AW. Incidence and location of melanocytomas. Arch Ophthalmol. 1967 Jan;77(1):61-6.

9 Jakobiec FA, Silbert G. Are most iris "melanomas' really nevi? A clinicopathologic study of 189 lesions. Arch Ophthalmol. 1981 Dec; 99(12):2117-32.
10 Shields JA, Demirci H, Mashayekhi A, Eagle RC Jr, Shields CL. Melanocytoma of the optic disk: a review. Surv Ophthalmol. 2006 MarApr;51(2):93-104.

11 Robertson DM, Campbell RJ, Salomão DR. Mushroom-shaped choroidal melanocytoma mimicking malignant melanoma. Arch Ophthalmol. 2002 Jan;120(1):82-5.

12 Shields JA, Shields CL, Eagle RC Jr, Santos C, Singh AD. Malignant melanoma arising from a large uveal melanocytoma in a patient with oculodermal melanocytosis. Arch Ophthalmol. 2000 Jul;118(7):990-3.

13 Shanmugam MP, Saxena M, Ramanjulu R, Tekwani P. Brachytherapy, a viable option of globe salvage in treatment of large ciliary body melanocytoma. Indian J Ophthalmol. 2014 Sep;62(9):966-8. 
14 Brownstein S, Dorey MW, Mathew B, Little JM, Lindley JI. Melanocytoma of the choroid: atypical presentation and review of the literature. Can J Ophthalmol. 2002 Jun;37(4):24752.

15 Lehman LJ, Hohberger GG, Buettner H, Campbell RJ. Necrotic melanocytoma of the choroid in a 2-year-old child. J Pediatr Ophthalmol Strabismus. 1997 Jan-Feb;34(1):40-3.

16 El-Harazi SM, Kellaway J, Font RL. Melanocytoma of the ciliary body diagnosed by fineneedle aspiration biopsy. Diagn Cytopathol. 2000 Jun;22(6):394-7.

17 Fineman MS, Eagle RC Jr, Shields JA, Shields CL, De Potter P. Melanocytomalytic glauco- ma in eyes with necrotic iris melanocytoma. Ophthalmology. 1998 Mar;105(3):492-6.

18 Bhorade AM, Edward DP, Goldstein DA. Ciliary body melanocytoma with anterior segment pigment dispersion and elevated intraocular pressure. J Glaucoma. 1999 Apr;8(2): 129-33.

19 Mazzuca DE Jr, Shields CL, Sinha N, Bianciotto CG, Fox G, Shields JA. Progressive retinal invasion and vitreous seeding from optic disc melanocytoma. Clin Exp Ophthalmol. 2012 Jan-Feb;40(1):e123-5.

20 Rummelt V, Naumann GO, Folberg R, Weingeist TA. Surgical management of melanocytoma of the ciliary body with extrascleral ex- tension. Am J Ophthalmol. 1994 Feb;117(2): 169-76.

21 Puri P, Prasad S, Rennie IG. Organized vitreous hemorrhage masquerading as an optic disc melanocytoma. Eur J Ophthalmol. 2003 Mar;13(2):215-7.

22 Shukla SY, Shields JA, Eagle RC, Shields CL. Transformation of optic disc melanocytoma into melanoma over 33 years. Arch Ophthalmol. 2012 Oct;130(10):1344-7.

23 Shields JA, Demirci H, Mashayekhi A, Shields CL. Melanocytoma of optic disc in 115 cases: the 2004 Samuel Johnson Memorial Lecture, part 1. Ophthalmology. 2004 Sep;111(9): 1739-46. 